\title{
DEGRADATION OF POLYCYCLIC AROMATIC HYDROCARBONS: A REVIEW
}

\author{
Peng, X. ${ }^{*}$ - Xu, P.-F. - Du, H. - TANG, Y. - Meng, Y. - YuAn, L. - ShEng, L.-P. \\ National and Local United Engineering Laboratory for New Petrochemical Materials and Fine \\ Utilization of Resources; Key Laboratory of Resource Fine-Processing and Advanced Materials \\ of Hunan Province; Key Laboratory of Chemical Biology and Traditional Chinese Medicine \\ Research (Hunan Normal University), Ministry of Education; College of Chemistry and \\ Chemical Engineering, Hunan Normal University, Changsha 410081, China \\ *Corresponding author \\ e-mail:xinp@hunnu.edu.cn
}

(Received $8^{\text {th }}$ Jun 2018; accepted $13^{\text {th }}$ Sep 2018)

\begin{abstract}
Polycyclic aromatic hydrocarbons (PAHs) are hydrocarbons composed of two or more benzene rings, and they are widely found in nature. The degradation of PAHs remains in a dynamic equilibrium, which has suffered from the increasing PAHs emissions under the continuous development of society. Therefore, the environmental pollution is getting increasingly serious. Many scholars have conducted researches on the degradation of PAHs. In this paper, the origin and properties of PAHs are introduced. Besides, the physical, chemical and biological methods for the degradation of PAHs were reviewed. Among them the biodegradation of PAHs has been especially analyzed. Meanwhile, the advantages and disadvantages of each method were described through comparison.
\end{abstract}

Keywords: PAHs, remove, physical methods, chemical methods, biological methods, characteristics

\section{Introduction}

Polycyclic aromatic hydrocarbons (PAHs) are organic compounds that consist of either at least two condensed benzene rings or pentad molecules that are arranged in various chemical configurations. PAHs are categorized as low molecular weight (LMW) and high molecular weight (HMW) PAHs based on molecular structure. The structures of LMW PAHs include two-rings structure and three-rings structure while those of HMW PAHs include at least four rings. The aqueous solubility of PAHs decreases almost linearly with the increase in molecular mass (Mahler et al., 2012).

PAHs feature high melting points, high boiling points, and the low aqueous solubility, which gradually decreases with the increase of molecular weight. At the same time, the high fat solubility enables PAHs to dissolve in organic solvents easily. PAHs are widely available as they can be released into the environment by nature or by human activities. Bio-combustion, such as the combustion of forest and grassland, is the main source of PAHs. In addition, the emission of PAHs is also caused by the combustion of gasoline and coal, as well as the combustion of industrial waste (Liu et al., 2008; Tiwari et al., 2013). Moreover, in urban areas, street dust and sewage contain not only PAHs but also heavy metals such as lead and copper. In areas abounded with coal mines, the formation of PAHs caused by incomplete combustion of bituminous coal leads to soil and air pollution (Brown and Peake, 2006; Sprovieri et al., 2007). When the PAHs are released into the air, it can be deposited in the soil or water. Road traffic emissions are related not only to vehicles exhaust but also to problems concerning tire, brake wear and re-suspended dust. Traffic re-suspended particles contain road dust accumulated from vehicle track-out from construction sites, water or 
wind erosion from nearby areas, tire and brake wear, oil leaks and spills, street repair materials and atmospheric deposition (Ravindra and Grieken, 2008). When humans eat plants that have been irrigated by the water, PAHs are transmitted to human through the food chain, and therefore harm humans. The toxicity of PAH compounds was noticed by many researchers. Researchers found that only a low concentration of PAHs could cause tissue mutations or cancer (Ruge et al., 2015). The U.S. Environmental Protection Agency has included 16 of them in the list of priority pollutants (naphthalene, acenaphtalene, acenaphtene, fluorene, phenanthrene, anthracene, fluoranthene, pyrene, benzo $(a)$ anthracene, chrysene, benzo $(b)$ fluoranthene, benzo $(k)$ fluoranthene, benzo (a) pyrene, indeno $(1,2,3-c d)$ pyrene, dibenzo $(a, h)$ anthracene, benzo $(g, h, i)$ perylene $)$ (Llobet et al., 2006).

The degradation of PAHs in nature is in a dynamic equilibrium. With the current industrial development, more and more PAHs are released, which has serious adverse effect on the environment and human health (Debajyoti et al., 2016). Therefore, more and more researchers pay their attention to PAHs and their degradation methods, including physical, chemical, biological methods and other methods (Cerniglia, 1992; Kalmykova and Moona, 2014). In this paper, the methods for the degradation of PAHs are reviewed and their advantages and disadvantages are summarized in turn.

\section{Physical methods}

Most PAHs are colorless or pale-yellow crystals, There are also some PAHs which are dark crystals. Besides, they feature high melting points and boiling points, while their vapor pressure is very small. In addition, they are mostly insoluble in water but soluble in benzene aromatic solvents, and slightly soluble in other organic with high adsorption affinity for solid media (Lamichhane et al., 2016). Therefore, the use of suitable adsorption and extraction materials can effectively degrade the PAHs in water, soil and sludge. Due to these properties, many researchers use adsorption, extraction and other physical methods to remove PAHs (Belo et al., 2017; Li et al., 2017).

\section{Sorption}

Sorption is one of the widely used methods of PAHs degradation, as PAHs possess low aqueous solubility and great sorptive ability for solid media. When the fluid is contacted with the porous solid, at least one type of component of the fluid accumulate on the solid surface. This process is called adsorption, which includes absorption, adsorption and ion exchange (Khattri and Singh, 2009; Lamichhane et al., 2016; Yuan et al., 2011). Several kinds of adsorbent media such as activated carbon, biochar and modified clay minerals have been largely used to remove PAHs from aqueous solution and to immobilise PAHs in the contaminated soils (Luna et al., 2016).

According to the functions of different kinds of adsorbent and adsorbed substance, there two types of adsorption: physical adsorption and chemical adsorption. In general, physical adsorption is a reversible process, while chemical adsorption is irreversible. Compared to other methods, adsorption is regarded as a good method to remove PAHs for its simple design, low cost and no secondary pollution. Therefore, choosing suitable adsorbent can solve the problems concerning the pollution of PAHs in water, soil and sludge (Yuan et al., 2010).

The choice of adsorbent material plays an important role in the degradation of PAHs. Pyrene, benzo (b) fluoranthene, benzo (k) fluoranthene, benzo (a) anthracene, indene 
$(1,2,3)$ pyrene, dibenzo $(\mathrm{a}, \mathrm{h})$ anthracene, benzene $(\mathrm{g}, \mathrm{h}, \mathrm{i})$ perylene were studied by adsorption experiments. It was found that activated carbon was an excellent adsorbent and could effectively remove PAHs (Lamichhane et al., 2016). Some scholars applied activated carbon to the absorption of PAHs pollutants in soil and sludge, and the removal rate reached $95 \%$. However, they did not take into account the fact that the metal ions in the sludge has effect on the adsorbent, which need to be noticed in actual operations (Oleszczuk et al., 2012). In fixed-bed column experiments, activated carbon is uesd by Luna et al. to carry out continuous adsorption and desorption experiments on PAHs in heavy naphthenic oil. It was found that the PAHs content in samples decreased from $8 \%$ to $3 \%$ (Luna et al., 2016).

Biochar is a kind of solid product produced by the pyrolysis of biomass in an anaerobic environment. Because of its porous structure and high surface area, biocarbon is conducive to the removal of PAHs in water and soil. The biochar can be produced by the pyrolysis of the coniferous, corn stover, peanut shell, wheat residue that occurs under the hypoxia condition and at the temperature ranging from 500 to $600{ }^{\circ} \mathrm{C}$ (Yongwoon et al., 2013). Black carbon, a kind of bio-carbon, does not function solely in the adsorption degradation of PAHs and other organic pollutants, but completes the process together with soil constituents. Rhodes et al. added black carbon to the soil, resulting in a significant reduction in the content of phenanthrene, which may be caused by the decrease in the concentration of aqueous solution containing phenanthrene owing to the adsorption of black carbon (Rhodes et al., 2008). Oleszczuk et al. added the biochar prepared at $600{ }^{\circ} \mathrm{C}$ to sludge containing napthalene, phenanthrene, anthracene, fluoranthene, pyrene, benzo (a) anthracene, chrysene, benzo (b) fluoranthene, benzo (k) fluoranthene, benzo (a) pyrene, indeno $(1,2,3 \mathrm{~cd})$ pyrene, benzo $(\mathrm{g}, \mathrm{h}, \mathrm{i})$ perylene and so on, and the dosage of biochar ranged from $0.5 \%$ to $10 \%$. It was found that biochar could reduce $57 \%$ of the PAHs in sludge (Oleszczuk et al., 2012). There are scholars who use charcoal in adsorption experiments on the pyrene and phenanthrene in the water, and the results show that the conversion rate of PAHs is more than 60\% (Yuan et al., 2010). The above studies show that the biochar has a good adsorption effect on most PAHs. It is worth mentioning that the biochar has better PAH adsorption effect on the PAHs with five- or six-ringed structures, than on those with two- to four-ringed structures. Besides, only few types of PAHs can achieve good adsorption effect, and biochar needs a very high temperature to convert from peanut shell and other materials. Maybe the more lowering conversion temperature is a key element to the future research direction for the researchers.

Magnetic nanomaterial is a kind of magnet containing hematite core and silica mesoporous material (Ríos and Zougagh, 2016). They can be used as adsorbent to remove PAHs. Yuxiong Huang et al. used this kind of material to adsorb acenaphthene in industrial wastewater. The results show that in $30 \mathrm{~min}$, the capture rate of acenaphthene reached $85 \%$ and the adsorption capacity reached $1060 \mathrm{mg} / \mathrm{kg}$. It was proved that the removal rate of magnetic nanometal ions is very high. Besides, the adsorption capacity of magnetic nanomaterial increases with the increasing $\mathrm{pH}$ and magnetic nanomaterial has excellent regeneration performance (Huang et al., 2016).

In addition to the abovementioned materials, grapheme oxide, electro spun nanofibers; laccase carrying electric fiber membrane can also be used for the adsorption of PAHs in the degradation (Feng et al., 2013; Niu et al., 2013). Through a large number of experiments, researchers have demonstrated that these materials can effectively adsorb and degrade PAHs. Moreover, in recent years, a combination of 
adsorbent materials and enzymes can not only achieve the physical adsorption, but also completely degrade the PAHs. Of course, there are many factors that affect the adsorption, such as temperature, $\mathrm{pH}$ value, humidity and so on. The removal rate of PAHs may vary under different conditions. Zhang et al. used black carbon to study the adsorption of pyrene in the soil. It was found that the adsorption capacity of pyrene was stronger when the soil moisture was higher, especially when the pyrene concentration was low. The adsorption of pyrene varies with different soil organic compounds. Compared with the black soil, the paddy soil has much higher polarity, therefore the adsorption capacity of black carbon to pyrene decreased more obviously (Zhang et al., 2013). By using plant residues to remove the PAHs in water, Xi et al. found that the higher the polarity of the aqueous solution, the more detrimental to the removal of PAHs. They removed the polar components by acid hydrolysis and the results show that the adsorption rate of phenanthrene increased by 6 to 18 times, and the adsorption rate of naphthalene, acenaphthene and pyrene increased by 6 to 8 times. It was also found that deodorized pine has the best adsorption capacity due to its lowest polarity (Zeledón-Toruño et al., 2007). Hiller et al. experimentally investigated the effect of temperature on the adsorption of naphthalene, phenanthrene and pyrene. When the temperature ranges from 4 to $27^{\circ} \mathrm{C}$, with the increase of temperature, the adsorption rate of naphthalene decreased by $27.3 \%$, and the adsorption rate of phenanthrene decreased by $17 \%$ while the adsorption rate of pyrene decreased by $27.4 \%$ (Hiller et al., 2008). It can be concluded that with the increase of temperature, the adsorption rate of PAHs decreased gradually. Some scholars prepared activated carbon by using orange peels and then conducted an adsorption test. They found that orange peel activated carbon can effectively remove the phenanthrene in the water (Chen et al., 2011). At the same time, they also investigated the factors affecting the adsorption. It was found than the adsorption rate of phenanthrene increased with the increase of the absorbent dose. When the absorbent dose was $18 \mathrm{mg}$, the phenanthrene was completely absorbed, therefore this adsorption dose was also found to be the best value. The experiments on the adsorption of phenanthrene at different $\mathrm{pH}$ values showed that the adsorption rate of the adsorbent decreased with the increasing $\mathrm{pH}$ value. Of course, some scholars pointed out that the $\mathrm{pH}$ value has little effect on the adsorption of some PAHs., Zeledon et al. (2007) used weathered lignite as an adsorbent to remove PAHs (fluorene, pyrene, benzo (k) fluoranthene, benzo (a) pyrene and benzo ( $\mathrm{g}, \mathrm{h}, \mathrm{i})$ perylene) in water. There was no significant difference in the adsorption rate of other contaminants at different $\mathrm{pH}$ levels except for that of fluorene, which is higher when $\mathrm{pH}$ value is small. When the $\mathrm{pH}$ value was 2 , the adsorption rate of fluorene was $86 \%$. As the $\mathrm{pH}$ value increased to 6 , the adsorption rate of fluorene dropped to $63 \%$. Therefore, we drew a conclusion that the results vary due to different conditions, which have different effects on different adsorbent materials. No matter what kind of material, we need to find the best conditions to achieve the best results.

\section{Extraction}

Extraction is also a commonly used method for treating PAHs in water and soil. The extraction agents include acetone, methanol, n-hexane and dimethyl ether (Lambropoulou, 2010; Noordkamp et al., 1997; Szulejko et al., 2014). Some scholars have demonstrated that these extractants can extract PAHs successfully. However, these solvents may cause re-contamination for the environment. Thus, more and more 
researchers are looking for other solvents or comprehensive methods to improve the extraction process and extraction rate.

Song et al. (2012) were studied the removal of phenanthrene in soil by combining ultrasound with soil cleaning. It was also found that increasing the ultrasonic time and the concentration of phenanthrene can be of great help to the removal of phenanthrene. According to the results, the removal rate of phenanthrene reached to $69.5 \%$ after 20 min of sonication. The investigation provides a viable method for the modification of highly contaminated soils. Sliva et al. used non-in situ extraction techniques to treat hydrocarbons contaminated soils. The contaminated soils was treated by a ethanolacetone-water ternary miscible systems, and a kinetic equilibrium was achieved after $10 \mathrm{~min}$. The extraction rate of the compound reached $85 \%$ and it increased by $8 \%$ with the increase of solid-liquid ratio from 1: 2 to 1: 8 (Silva et al., 2005).

More and more scholars use vegetable oils as extractants in the extraction of PAHs, because they are naturally non-toxic, cheap and feasible to be used for biodegradation. Lau et al. (2014) found that peanut oil is an excellent extractant to remove PAHs. They used peanut oil whose concentration ranges from $2.5 \%$ to $20 \%$ to extract the anthracene from garden soil, and the extraction rate reached higher than $90 \%$. At the same time, through experiment, they found that the optimum $\mathrm{pH}$ was 6-7. In addition, the extraction rate of PAHs increased from $51.5 \%$ to $81.4 \%$ when the temperature rose from 20 to $60{ }^{\circ} \mathrm{C}$, which indicated that when peanut oil is the extractant, the extraction rate of PAHs increased with the increase of temperature. Some scholars used sunflower oil to extract PAHs so as to repair the soil (Gong et al., 2005). The results show that sunflower oil has excellent ability to remove PAHs, especially for soil with a high concentration of PAHs, and the removal rate was close to $100 \%$. Different vegetable oils have different If the vegetable oils that used for extraction are different, the extraction rates of the same $\mathrm{PAH}$ as different as well. Lau et al. extracted the fluoranthene and phenanthrene with palm kernel oil and soybean oil. It was demonstrated that using palm kernel oil for extracting PAHs can achieve a higher extraction rate compared with using soybean oil. Besides, with these two vegetable oils being used as extractant, the extraction rates of PAHs was lower when gravel was highly polluted, compared with that of PAHs when gravel was low-polluted (Lau et al., 2014). The investigation also indicated that the difference of temperature affects the extraction rates of fluoranthene and phenanthrene. Especially at a high temperature, the extraction rate of fluoranthene is higher than that of phenanthrene. When the soybean oil was utilized to extract, PAHs, the extraction rate of fluoranthene was $0.7 \%$ and $4.75 \%$ higher than that of the phenanthrene at the temperature of $30{ }^{\circ} \mathrm{C}$ and $70{ }^{\circ} \mathrm{C}$ respectively. When the palm kernel oil was used as extractant, the extraction rate of anthracene was $3.35 \%$ and $1.35 \%$ higher than that of fluoranthene at the temperature of $30{ }^{\circ} \mathrm{C}$ and $70{ }^{\circ} \mathrm{C}$ respectively (Von et al., 2012). Sanchez-Trujillo et al. studied the biodegradation of PAHs contaminated soils by using cyclodextrin as an extractant (Sáncheztrujillo et al., 2013). It is proved that cyclodextrin has a good degradation effect on PAHs. They studied the PAHs composed of three benzene rings (anthracene, phenanthrene, fluorene, acenaphthene, etc.) with chemically modified cyclodextrin, $\mathrm{Ca}\left(\mathrm{NO}_{3}\right)_{2}$ electrolyte solution and natural cyclodextrin utilized as extractants. It was found that the chemically modified cyclodextrin achieved the highest extraction rate of PAHs, about $10 \%$ higher than those achieved by the other two extractants. 


\section{Chemistry methods}

In summary, the two physical methods of adsorption and extraction have significant effects on the removal of PAHs. However, there is no chemical change in these physical processes. These materials simply transfer PAHs from water or soil, and the PAHs cannot be completely removed. Therefore, chemical methods have been used to degrade PAHs.

Physical adsorption and extraction have a significant effect on the degradation of PAHs, but these physical processes are time-consuming and inefficient. Therefore, many researchers have paid their attention to chemical methods. At present, the most important approaches to the PAHs degradation are oxidation and photocatalysis (RubioClemente et al., 2014).

\section{Oxidation}

It is well known that potassium permanganate is highly oxidizing, therefore some researchers used it to deal with PAHs contaminated soil. Brown et al. utilized potassium permanganate to deal with potassium the benzo (a) pyrene, chrysene, fluoranthene, phenanthrene, and pyrene in the soil. After $30 \mathrm{~min}$, the content of benzo (a) pyrene, pyrene, phenanthrene and anthracene were decreased $72.1 \%, 64.2 \%, 56.2 \%$ and $53.8 \%$, respectively. Under the same conditions, fluoranthene and chrysene were reduced by at least $13.4 \%$ and $7.8 \%$, respectively. According to the investigation, the order of the oxidation degradation rates of potassium permanganate for these six kinds of PAHs can be listed as: benzo (a) pyrene> pyrene> phenanthrene> anthracene> fluoranthene> chrysene (Brown et al., 2003). The results show that the effect of potassium permanganate on the degradation of low molecular weight PAHs is obvious. However, the adverse effects of potassium permanganate on aquatic plant are severe.

Ozone has a strong oxidizing power and it is mostly used in the degradation of PAHs. However, many researchers found that the shortcomings of ozone will be revealed if ozone is used alone. Many studies show that the degradation efficiency of the combination of ozone and certain reagents is better than that of ozone (Bouzid et al., 2017; Ji et al., 2018).

Bernal-Martinez et al. used ozone to conduct anaerobic digestion experiments on 12 kinds of PAHs such as anthracene, phenanthrene and pyrene, so as to study the efficiency of ozone degradation of PAHs in sludge (Bernalmartinez et al., 2007). They conducted three comparative experiments. In the first experiment, oxidant was not added to the samples. On the contrary, the oxidant was the only thing that had been added to the samples of the second experiment. Moreover, samples of the third experiment contained not only oxidant but also tetrabutyl phenol. Under the same experimental conditions, the comparison of the three experiments showed that the oxidant had the most obvious degradation effect on PAHs. The other two groups of sample also showed the degradation of PAHs, but the effect was not obvious. At the same time, the amount of added oxidant is also critical factor. Through anaerobic digestion experiments, they found that the optimum ozone dose is of $0.11 \mathrm{~g}$ per gram of sludge.

Oxidative degradation of PAHs has proven to be an effective means by many researchers, but some scholars have suggested that relying on ozone oxidation alone is less efficient. Brown also proposed to use ultraviolet radiation or the addition of other oxidants such as hydrogen peroxide to improve ozone oxidation rate (Brown et al., 
2003). Beltran et al. improved the ozonation of fluorene, phenanthrene and acenaphthene by UV radiation and the addition of hydrogen peroxide. Experiments show that the use of ultraviolet radiation and the addition of hydrogen peroxide do not always play a role in the degradation of PAHs. These method can only improved the efficiency of fluorene degradation and phenanthrene degradation, and there is almost no effect on acenaphthene (Beltrán et al., 1996).

With a method combining UV radiation and ozone, Ledakowicz et al. (2014) also conducted degradation experiments on benzo (a) pyrene, chrysene and fluorene in water. The mechanism of this process is listed as follows (Eqs. 1-7):

$$
\begin{gathered}
\mathrm{O}_{3}+h v-\rightarrow \mathrm{O}_{2}+\mathrm{O}(1 \mathrm{D}) \\
\mathrm{O}(1 \mathrm{D})+\mathrm{H}_{2} \mathrm{O}-\rightarrow \mathrm{H}_{2} \mathrm{O}_{2} \\
\mathrm{H}_{2} \mathrm{O}_{2}+\mathrm{h} v-\rightarrow 2 \cdot \mathrm{OH} \\
\mathrm{H}_{2} \mathrm{O}_{2} \rightarrow \mathrm{HO}_{2}^{-}+\mathrm{H}^{+} \\
\mathrm{O}_{3}+\mathrm{OH}^{--} \rightarrow \mathrm{HO}_{2}^{-}+\mathrm{O}_{2} \\
\mathrm{O}_{3}+\mathrm{HO}_{2}^{-}-\rightarrow \mathrm{HO}_{2} \bullet+\mathrm{O}_{3}- \\
\mathrm{PAH}+\mathrm{O}_{3}+\mathrm{h} v+\bullet \mathrm{OH}-\rightarrow \text { products }
\end{gathered}
$$

Among them, $\bullet \mathrm{OH}, \mathrm{HO}^{2-}, \mathrm{O}_{3} \bullet$ achieved a major oxidation. The results show that the degradation rate of benzo (a) pyrene reached $85 \%$ with ultraviolet radiation and ozone, and the degradation rate of chrysene and that of fluorene reached $90 \%$. As for the method that using ozone alone, the degradation rates of benzo (a) pyrene, chrysene and fluorene were $10 \%, 70 \%$ and $50 \%$, respectively. As for the method that using UV radiation alone, the degradation rates of benzo (a) pyrene, chrysene and fluorene were $80 \%, 40 \%$ and $55 \%$, respectively. Because of the hydrogen ions emerging in the reaction process, the $\mathrm{pH}$ value has a certain effect on the oxidation process, and this effect needs to be further investigated. In contrast, combining UV radiation with ozone is more effective for the degradation of PAHs. Eberius et al. studied the aromatic core structures by using the mass-spectra. They found that the final product of pyrene is benzene with the possible functional groups such as carboxyl (Eberius et al., 1997). Fenton $\left(\mathrm{Fe}_{2}+/ \mathrm{H}_{2} \mathrm{O}_{2}\right)$ has been widely used in the treatment of organic pollutants (Pérez et al., 2002). The reaction of divalent iron ions in Fenton and hydrogen peroxide generates oxidative hydroxyl radicals and lead to the formation of ferric ions (Eq. 8). The main oxidative component of the Fenton reagent is hydroxyl radicals.

$$
\mathrm{Fe}^{2+}+\mathrm{H}_{2} \mathrm{O}_{2} \rightarrow \mathrm{Fe}^{3+}+\mathrm{OH}^{-}+\mathrm{OH}
$$

Homem et al. demonstrated the feasibility of removing benzo (a) pyrene (BaP) in water with Fenton reagent (Homem et al., 2014). They also researched the effect of temperature, $\mathrm{pH}$ value, divalent iron ion concentration and the concentration of hydrogen peroxide on the removal efficiency of $\mathrm{BaP}$. As the temperature increased from 30 to $70{ }^{\circ} \mathrm{C}$, the removal rate of $\mathrm{BaP}$ increased from 90 to $100 \%$. But $\mathrm{pH}$ value has little 
effect on the removal rate of $\mathrm{BaP}$. The effect of divalent iron ion concentration is similar to that of temperature, as the removal rate of $\mathrm{BaP}$ increased with the increase of divalent iron ion concentration. The increase in the concentration of hydrogen peroxide will improve the removal rate, but an excessive concentration will contrarily reduce the removal rate. Homem proved that Fenton had a good effect on the removal of PAHs. With an initial concentration of $50 \mathrm{mg} \mathrm{L}^{-1}, 90 \%$ removal was achieved, while with the concentration of $150 \mathrm{mg} \mathrm{L}^{-1}$, only $80 \% \mathrm{BaP}$ was eliminated. Therefore, it can be concluded that advanced oxidation technology is more helpful to PAHs degradation than conventional oxidation technology.

\section{Photocatalytic}

Photocatalysis is also an important way to remove organic matter such as PAHs and other pollutants. Photocatalytic materials consist of titanium dioxide, zinc oxide, silicon dioxide and so on. Among them, titanium dioxide is extensively applied because of its high degree of oxidability and stability (Jiang et al., 2018, 2017; Woo et al., 2009).

Veréb et al. used UV lamps as light sources to perform degradation experiments on phenanthrene in water. Titanium dioxide absorbs the energy produced by ultraviolet light so as to produce electrons. Besides, the reaction of positive charge and water produces hydroxyl radicals and hydrogen ions, while the negative charge reacts with oxygen and hydrogen ions to form a peroxy radical (Veréb et al., 2012). Hydroxy radicals and peroxygen have strong oxidizing properties, which play an important role in photocatalytic degradation of phenanthrene. The results show that titanium dioxide photocatalytic materials were the most effective for the removal of phenanthrene. Besides, the final oxidation product of phenanthrene is carbon dioxide and so on (Wen et al., 2002).

Different experimental conditions may have an effect on photocatalytic efficiency. Lair et al. (2008) used titanium dioxide as the photocatalytic material for naphthalene degradation experiments. At the same time, they studied the impact of the photoelectron flux, temperature, $\mathrm{pH}$ value and inorganic ions on the photocatalytic efficiency. When the received photoelectron flux rises from 0 to $10^{16}$ photons per second, the degradation rate also increases. When this range is exceeded, the amount of photoelectron flux has no effect on the degradation rate. When the temperature increases from 10 to $4{ }^{\circ} \mathrm{C}$, since the photoactivation is independent of the thermal activation, the temperature has no effect on the photocatalytic rate. Under the strong acid or strong alkaline conditions, the degradation rate will be reduced. The study also pointed out that carbonates and carbonates will inhibit photocatalysis.

Similar to titanium dioxide, zinc oxide is also a kind of semiconductor material., Currently, in the field of photocatalysis, titanium dioxide materials are widely the most widely used materials, while people have little knowledge of Zinc Oxide materials. Zinc oxide is a kind of wide band gap semiconductor material with a $3.37 \mathrm{eV}$, and its exciton binding energy at room temperature is $60 \mathrm{eV}$ (Ramasamy et al., 2013). In the degradation of PAHs, using oxidation alone and using photocatalysis alone can improve the efficiency. Therefore, combining these two methods may have a better effect. It has been experimentally demonstrated by Vela et al. that zinc oxide and titanium dioxide have excellent effects on removing PAHs in water. They applied a method concerning the combined use of $\mathrm{ZnO}$ and $\mathrm{Na}_{2} \mathrm{~S}_{2} \mathrm{O}_{8}$ to the degradation of PAHs in groundwater. After comparison, it was found that compared to utilizing photocatalytic method alone, the use of the combined method improved the total organic carbon reduction by $21 \%$ 
(Vela et al., 2012). The combination of photocatalysis and oxidation seems to have a better effect.

From the above results, it is not difficult to conclude that the chemical method has a significant improvement in the degradation rate of PAHs compared to physical methods. However, when use photocatalysis alone or use ozone alone, the efficiency of PAHs degradation is lower than that of adding other oxidants together. Moreover, it is necessary to pay attention to the secondary pollution caused by intermediate products.

\section{Biodegradation}

In recent years, with the improvement of environmental awareness, the concern of many researchers has gradually shifted from physical and chemical degradation methods to biodegradable methods. Because of no secondary pollution, low cost and simple operation and so on, biodegradation methods are considered as the best ways to deal with PAHs. Fungi, bacteria, and plants have good abilities to degrade PAHs (Haritash and Kaushik, 2009; Kronenberg et al.; 2017; Nzila, 2018).

\section{Plant}

Plants belong to autotrophic organisms that features using light and carbon dioxide for photosynthesis. Because the roots of plants can absorb some toxic compounds, plants function as natural cleaning systems. Therefore, for the purpose of repairing PAHs contaminated soils plants can be applied to the degradation of PAHs (Alagic et al., 2015; Chen et al., 2011). Alagić et al. demonstrated that plant has the ability to degrade $\mathrm{BaP}$, which is mainly due to a series of biotransformation of the enzyme system in plant roots (Alagić et al., 2016). Chen et al. labeled pyrene with ${ }^{14} \mathrm{C}$, and evaluated the degradation abilities of tall fescue (Festuca arundinacea) and switchgrass (Panicum virgatum L.) (Yenchih Chen et al., 2003). After 190 days, 37.7\% and 30.4\% of pyrene were mineralized in the soil where tall fescue (Festuca arundinacea) was planted and where switchgrass (Panicum virgatum L.) was planted, respectively. Only $4.3 \%$ of the pyrene in the soil without the two plants was mineralized. At the end of the experiment, the residual quantity of pyrene in the two kinds of soil was only 7.6 and $8.7 \%$, respectively. Somtrakoon et al. studied the degradation of anthracene and fluorene that affected by sweet corn, cucumber, and winged bean. They transplanted these three plants to the soil that contained containing $138.9 \mathrm{mg} / \mathrm{kg}$ of anthracene and $95.9 \mathrm{mg} / \mathrm{kg}$ of fluorene (Somtrakoon et al., 2014). After 15 to 30 days, the plant elongation, plant weight, chlorophyll content, and PAHs content in soil and plant tissue were determined. The results show that winged bean achieved the best degradation rate of anthracene and fluorene, which were degraded by $92.2 \%$ and $75.8 \%$, respectively. Besides, $91.2 \%$ and $95.9 \%$ of the anthracene and fluorene degraded in the soil mixed with corn and four ribbean. Corn and cucumber grown in soil After 15 days, $14 \%$ of fluorene remained in the corn-planted, and $17.3 \%$ of fluorene remained in the cucumber-planted soil. The degradation of fluoranthene, pyrene, and a mixture of fluoranthene and pyrene affected by Scenedesmus platydiscus, Scenedesmus quadricauda, Chlorella vulgaris, and Selenastrum capricornutum has been studied by scholars. In the experiment, the concentrations of fluoranthene, pyrene, and a mixture of fluoranthene and pyrene were all $1 \mathrm{mg} / \mathrm{L}$. The results show that Selenastrum capricornutum achieved the highest conversion efficiency, and the removal rate of PAHs reached $78 \%$ in 7 days. However, 
among these four kinds of algae, vulgaris achieved the lowest efficiency of, the removal rate was only $48 \%$ (Lei et al., 2007).

\section{Bacteria}

Bacteria are microorganisms that are critical to the degradation of organic pollutants. It is well known that many bacteria can accelerate the degradation of PAHs with a very high efficiency (Kuppusamy et al., 2016; Mohanrasu et al., 2018). Bacteria can produce dioxygenase, which enable bacteria to facilitate PAHs degradation through the enzyme catalysis. Subsequently, the oxygen is added to the benzene ring, and the formation of the $\mathrm{C}-\mathrm{O}$ bond is achieved. Moreover, after hydrogenation and dehydration, the benzene ring is eliminated, and the degradation is completed (Cerniglia, 1992). Xia et al. found that Pseudomonas aeruginosa WJ6 can produce surface active agents, fermudamycin and lichen proteins. It was concluded that Pseudomonas sp. WJ6 excels in facilitating the degradation of PAHs. During the 20-day period, the fluorene, naphthalene and phenanthrene in the culture dish were decreased significantly by $39.45 \%, 23.14 \%$ and $21.93 \%$, respectively. The degradation rate of pyrene affected by Pseudomonas sp. WJ6 to was only $19.50 \%$ for two-ring PAHs and three-ring- PAHs (Xia et al., 2014). Romero et al. isolated yeast strains from contaminated rivers and studied their ability to facilitating the degradation of tricyclic PAHs. Phenanthrene is the only carbon source, while red yeast and Pseudomonas aeruginosa are the main microbes. The researchers added different amounts of phenanthrene to the mineral medium containing ethanol. At a temperature of $3{ }^{\circ} \mathrm{C}$, the samples were irradiated with ultraviolet light for $40 \mathrm{~min}$ so that the ethanol volatilized subsequently. They found that the medium phenanthrene underwent an almost complete degradation after one-month incubation period (Romero et al., 1998). Some scholars conducted the same experiments, and they drew the conclusion that the culture of the phenanthrene is not completely degraded and the degradation rate was only about $60 \%$, which is different from Romero's finding. Rahman et al. studied the ability of immobilized bacteria to degrade hydrocarbons (Rahman et al., 2006). Rahman et al. planted hydrocarbon-degrading bacterial strains in alginate and are cultured in contaminated artificial seawater. After 30 days, it was found that the pollutants contaminated by petroleum hydrocarbons were removed effectively. Evidently, the immobilized bacteria in the alginate could be used to degrade the hydrocarbons effectively. As PAHs are hydrocarbons, it can be concluded that immobilized bacteria can be of great help to the degradation of PAHs. For the degradation of PAHs, Rehmann et al. proposed a method concerning the use of the mycobacterium strain KR2. Using Mycobacterium strain KR2, they investigated the degradation ability of pyrene-contaminated soils. Pyrene was the sole carbon source, and the mycobacterial strain KR2 was the only strain (Rehmann et al., 1998). The experiment was carried out at a temperature of $20^{\circ} \mathrm{C}$. After 8 days of incubation, the degradation rate of pyrene reached $60 \%$. The degradation products of pyrene are cis4,5-pyrene diethylene glycol, 4,5-phenylene dicarboxylic acid, 1-hydroxy-2-naphthoic acid, 2-carboxybenzaldehyde, phthalic acid and the original Catechins, etc., and these products are easy to remove. It can be concluded that the use of mycobacteria is also effective to degrade PAHs.

Dean-Ross et al. used the mycobacterial strain to determine the ability of bacteria through the mineralization of PAHs (Dean-Ross et al., 2002). The mineralization rate of pyrene was $0.044 \mathrm{mg} / \mathrm{L}$, and the mineralization rate of anthracene was $0.470 \mathrm{ug} / \mathrm{L}$. At the same time, they also found a degradation method of fluoranthene. Among the two 
strains, the metabolism of fluoranthene occurred on the fused ring of fluoranthene molecules. The degradation products of fluorinated anthracene mineralized by mycobacteria were 9-fluorenone-1- carboxylic acid, and the degradation product of fluoranthene mineralized by Rhodococcus is $\alpha$-(carboxymethylene) fluorene-1carboxylic acid. Muangchinda et al. studied the degradation of PAHs in river sediments of the Chao Phraya River Basin (Muangchinda et al., 2017). They isolated two actinomycetes in the river sediments: Arthrobacter and Rhodococcus. These two bacteria showed a high degradation activity in the culture medium. The concentration of fluorene, phenanthrene and pyrene in the medium was initially $300 \mathrm{mg} / \mathrm{kg}$, and the concentration of acenaphthene was $600 \mathrm{mg} / \mathrm{kg}$. After 70 days of incubation, fluorene and phenanthrene were all degraded and the degradation rates of pyrene and acenaphthene reached 50\%. It was proved that Agrobacterium and Rhodococcus sp. play important roles in the degradation of PAHs with high concentration. Jin et al. selected two strains (JB1 and JB2) from the contaminated wetland sediments and fixed them on the cinder, which means the bacterial cells is immobilized (Jin et al., 2017a). The degradation rate of benzo (a) pyrene reached $71.9 \%$ after 40 days in the medium, while the degradation rate of free cells was only $47.7 \%$. The reason is that the cinder has a large specific surface area and pore size, which is conducive to the aerobic degradation of strains. It also indicates that the carrier material plays an important role in the degradation of PAHs. Tetracyclic pyrene has a low biological activity and a strong biological resistance. Strain F14 was constructed by protoplast fusion of Sphingomonas GY2B and Pseudomonas sp. GP3A. Lu et al. studied the degradation of pyrene with F14 (Lu et al., 2014). When the concentration of pyrene was $15 \mathrm{mg} / \mathrm{L}$, the degradation rate of pyrene was $40.4 \%$ in F14 medium, while only $9.8 \%$ of the pyrene in the GP3A was degraded. When the concentration of pyrene was $50 \mathrm{mg} / \mathrm{L}$, the degradation rates of pyrene was $37.1 \%$ and $22.3 \%$, respectively. Experiments showed that the F14 strain constructed by protoplast fusion has better ability to degrade than the original strain. While GY2B is inefficient to degrade pyrene. They also found that when several kinds PAHs were mixed together, the degradation velocity and degradation rate has improved. When naphthalene and phenanthrene were simultaneously added to the medium, $42 \%$ of the pyrene degraded in $120 \mathrm{~h}$. After $240 \mathrm{~h}, 79 \%$ of the pyrene degraded. Contaminated soil, sludge and water generally contain metal ions, which are likely to affect the degradation of PAHs. Chen et al. studied the role of copper ions in the degradation of PAHs by the utilization of bacteria (Chen et al., 2013). The degradation of $\mathrm{BaP}$ was studied by using $\mathrm{BaP}$ as the carbon source and using matrix of coexisting maltose and copper ion. The initial BaP concentration was $1 \mathrm{mg} \mathrm{L}^{-1}$, subsequentlly, after 3 days at a temperature of $30{ }^{\circ} \mathrm{C}$ and natural $\mathrm{pH}, 45 \%$ of $\mathrm{BaP}$ was degraded. When the temperature rose to $35{ }^{\circ} \mathrm{C}$, the degradation rate was $48 \%$ after two days. The different contents of copper ions also affect the degradation of $\mathrm{BaP}$. When the concentration of copper ions is $2 \mathrm{mg} \mathrm{L}^{-1}$, the degradation rate of $\mathrm{BaP}$ can be improved slightly. When the concentration of copper ions is $100 \mathrm{mg} \mathrm{L}^{-1}$, only $5 \%$ of $\mathrm{BaP}$ is degraded and the removal rate of copper ions is $70 \%$. Because a portion of the copper ions converted to copper hydroxide precipitation, which inhibited the activity of bacteria, therefore the degradation rate of $\mathrm{BaP}$ decreased. Doping some sucrose as a carbon source can make Maltobacter function better, which facilitates PAHs degradation. Some plants contain bacteria, and they are called endophytic plants. When the soil is contaminated by PAHs, these bacteria can improve soil quality. For example, Aims Endophytic bacteria that are widely found in plants. Sun et al. extracted 
Staphylococcus BJO6 from plants, and the concentration of pyrene in the medium was $50 \mathrm{mg} / \mathrm{L}$ (Sun et al., 2014). After 15 days, 56\% of the pyrene was degraded in the medium. Ryegrass and bamboo shoots are endophytic plants from which BJ06 can be extracted. It is found that the content of pyrene in the ryegrass-planted soil and bamboo shoots-planted soil is $31.01 \%$ and $44.22 \%$ lower than that planting non - endemic plants. Evidently, Staphylococcus BJO6 can remove the PAHs in the soil effectively, which is an efficient way to reduce PAHs from the beginning of the food chain. Some scholars have found Leclercia adecarboxylata PS4040, which is isolated from oil and contaminated soil. When pyrene is used as a carbon source and affected by Leclercia adecarboxylata PS4040, 61.5\% of the pyrene in the culture medium was degraded after 20 days of observation. After 5 days, the metabolites of pyrene were 1-hydroxypyrene. Besides, through high performance liquid chromatography and magnetic resonance, it was found that the 1-hydroxypyrene could also be used as a carbon source and can produce acid or aldehyde by being further mineralized by Leclercia adecarboxylata PS4040 (Sarma et al., 2010).

\section{Fungi}

At present, it is found that several kinds of fungi help to maintain the sustainable degradation of PAHs contaminants. In recent years, the study of fungal degradation of PAHs has been further improved (Cutright, 1995; Shi et al., 2018; Szczepaniak et al., 2015). Aspergillussp, Trichocladium canadense and Fusarium oxysporum are widely used to degrade low-molecular-weight PAHs, while Verticillium sp., and Areremonium $s p$. are used to degrade high-molecular-weight PAHs (Silva et al., 2009). Fungi can produce enzymes, which facilitates the degradation of PAHs. Kristanti et al. found that enzymes are a key factor in the degradation of polycyclic aromatic hydrocarbons affected by fungi (Kristanti and Hadibarata, 2015). They used Pestalotiopsis sp. W15 to carry out a degradation experiments on fluorene. Pestalotiopsis sp. W15 could produce laccase. After 23 days of experiment, fluorene was completely degraded and the degradation products were salicylic acid and indanone. In order to facilitate the production of laccase, Tween 80 and Brij35 were added to the culture medium. The results show that the addition of Tween 80 could facilitate the production of laccase. When, Waszak et al. studied BaP degradation by using the mixtures of several kinds of bacterial and fungal to achieve the degradation of pollutants. The mixtures contained Pseudomonas aeruginosa, Candida albicans, Aspergillus flavus, and Fusarium sp. (Waszak et al., 2015). With $\mathrm{BaP}$ as carbon source and its concentration of $16 \mu \mathrm{L} / \mathrm{g}$, the degradation rate of $\mathrm{BaP}$ was about $65.51 \%$ after 42 days of incubation in an oven at a temperature of $35^{\circ} \mathrm{C}$. Hadibarata et al. used white-rot fungus Armillaria sp. F022 in the study of fluoranthene (Hadibarata and Kristanti, 2014). The genus Armillaria is produced in the process of degradation of ligninolytic enzymes, namely laccase and 1,2dioxygenase. These two enzymes play key roles in the degradation process. In the experiment, different concentrations of Armillaria sp. F022 were added to culture medium. After 30 days of incubation, when F022 concentration is $10 \mathrm{mg} / \mathrm{L}$, the fluoranthene was completely degraded. The degradation rate decreased with the increase of F022 concentration. When the concentration of F022 was $20 \mathrm{mg} / \mathrm{L}$ and 30 $\mathrm{mg} / \mathrm{L}$, the degradation rate of fluoranthene was $79.2 \%$ and $61.6 \%$, respectively.

Zhang et al. investigated the degradation rates of different PAHs affected by the same kind of fungus under the same conditions (Zhang et al., 2015). They studied the metabolic transformation of anthracene and pyrene affected by Pangnoporus 
sanguineus H1. Under the vivo conditions, the degradation rate of anthracene reached $67.5 \%$ and the degradation rate of pyrene was $31.1 \%$. When the tert-butyl ether was added to the samples, it enhanced the activity of laccase. Therefore, the degradation rate of anthracene increased to $73.1 \%$ while the degradation rate of pyrene declined, accurately, only $5.3 \%$. In the in vitro conditions, $59.9 \%$ of the anthracene was degraded in the extracellular fluid. Subsequently, after adding 2, 2' -azabis (3ethylbenzothiazoline-6-sulfonate) to the anthracene sample, the degradation rate increased to $92 \%$, but pyrene cannot degrade in the extracellular fluid. It can be concluded that the ability of Pangnoporus sanguineus $\mathrm{Hl}$ to facilitate the degradation of anthracene is better than that to facilitate the degradation of pyrene. There was no laccase in the extracellular fluid, which demonstrates that laccase is critical to the degradation of PAHs. This study has fully demonstrated that fungi can produce laccase and degrade PAHs due to the oxidative catalytic ability of laccase, and therefore provides a good basis for researchers to study the degradation of PAHs utilizing laccase. Garonet et al. studied the degradation of maltosyl-cyclodextrin-modified fluorine (Garon et al., 2004). They screened 47 strains from the fungus to find the most effective strains to be used in the process of biological proliferation, and they finally selected Trichoderma spore bacteria. With the presence of Trichoderma sp., more than $90 \%$ of the fluorene was degraded after $288 \mathrm{~h}$. However, it takes $576 \mathrm{~h}$ for fluorene degradation rate to reach $90 \%$ without the fungal proliferation process. Hilton et al. isolated 146 filamentous fungal strain in the separation of contaminants from the Amazon region and named them from S1 to S146 (Souza et al., 2016). The results show that only Megasporoporia sp. S47 and Sordariales S69 showed the highest activity of laccase and manganese peroxidase during $\mathrm{BaP}$ degradation. Besides, Megasporoporia sp. $S 47$ achieved the best results, and it enabled the degradation rate of $\mathrm{BaP}$ to reach $54 \%$. While the other strains reached only about 23\%. The fungal strain Aspergillus BAP14 was isolated from coastal sediments by $\mathrm{Wu}$ et al. and it was used in the degradation of $\mathrm{BaP}$ (Wu et al., 2009). In the experiment, the initial concentration of $\mathrm{BaP}$ was $10 \mathrm{mg} / \mathrm{L}$. After 3 days of incubation, $30 \%$ of $\mathrm{BaP}$ was degraded. After 9 days, BaP was degraded by $60 \%$. When sugar and other carbon compounds are added to the culture medium, especially lactose and naphthalene, the degradation rate increases significantly. The changes in $\mathrm{pH}$ value in the culture medium has little effect on the degradation rate. Monascus is a kind of white rot fungus, which can be easily isolated from the rotting woods. Hadibarata et al., investigated the degradation of naphthalene by Monascus and tested the metabolites (Hadibarata et al., 2013). Monascus and naphthalene was added to the culture medium for 14 days, and naphthalene was the only carbon source. Subsequently, naphthalene metabolites were tested by the use of ultraviolet, thin layer chromatography and gas chromatography-mass spectrometry, and the metabolites included 1,4-naphthoquinone, benzoic acid and catechol. At the same time they also detected enzyme, which plays an important role in the degradation, including manganese peroxidase, lignin peroxidase, laccase, 1,2-dioxygenase and 2,3dioxygenase. Oil spill is also a source of PAHs that pollutes the oceans. Michel et al., extracted eight fungi from the oceans to study their influence on the degradation of PAHs (Passarini et al., 2011b). In the experiment, pyrene and benzo (a) pyrene were carbon sources. With the use of Aspergillus sclerotiorum CBMAI 849, the degradation rate of pyrene was up to $99.7 \%$ after eight days. After a 16-day use of Aspergillus sclerotiorum CBMAI 849, the optimum degradation rate of benzo (a) pyrene was achieved, and the degradation rate was $76.6 \%$. The degradation rate of benzo (a) pyrene 
achieved by Mucor racemosus CBMAI 847 was more than 50\%. The metabolites of pyrene and $\mathrm{BaP}$ being dealt with these fungi are pyrenyl sulfate and benzo (a) pyrenyl sulfate, respectively. This study provides an effective remedy for the PAHs pollution of marine. Arun et al., found that Pseudomonas $s p$. is the most potent fungus that degrades pyrene, and the degradation rate of pyrene is $42 \%$ (Arun et al., 2008). In the subsequent experiment, they added $\mathrm{C}$. versicolor and P. ostreatus active agents to the culture medium. The results show that the degradation rate of pyrene reached $93.7 \%$, which indicated that the surfactant was important for improving the ability of fungi to facilitate PAHs degration. The degradation rate is not only related to surfactant, but also related to the role of enzymes. The degradation of pyrene was positively correlated with the potential of lignin peroxidase (Lip), manganese peroxidase (MnP) and laccase, but it was not related to the activity of the enzyme. Da et al. screened Cyclothyrium sp., which has a positive impact on the degradation of pyrene. In medium mixed with PAHs, Cyclothyrium sp. also exhibited good ability to improve degradation efficiency. Da selected four kinds of fungi, including Cyclothyrium sp.; Penicillium simplicissimum; Psilocybe sp. and a sterile mycelium, the degradation rate and metabolites of pyrene in culture medium were studied by applying HPLC and UV. In the culture medium, $48 \%$ pyrene was converted to trans-4,5-dihydrogenated diol, pyrene-1,6-quinone, pyrene-1,8quinone and 1-hydroxypyrene. After $192 \mathrm{~h}$ of incubation, influenced by Cyclothyrium sp., the degradation rates of phenanthrene, pyrene, anthracene and benzo (a) pyrene are $70 \%, 74 \%, 59 \%$ and $38 \%$, respectively(Da et al. 2004).

In recent years, many non-white rot fungi strains have been observed to be highly resistant to adverse environment. Many non-white rot fungi have been proved to have the ability to degrade PAHs (Marcourrea and Aranda, 2015; Veignie et al., 2004). Fusarium sp. 's (Strain E033) excellent ability to degrade BaP has been demonstrated by Chulalaksananukul et al. (2006). According to the investigation, the initial concentration of $\mathrm{BaP}$ in the medium was $100 \mathrm{mg} / \mathrm{L}$, and $65 \%$ to $70 \%$ of the $\mathrm{BaP}$ was degraded after 30 days of culture at a temperature of $32{ }^{\circ} \mathrm{C}$. In addition, there were two degradation products: dihydroxybenzo (a) pyrene and benzo (a) pyrene quinone. Increasing air and carbohydrates can improve degradation efficiency of PAHs. Anaisell et al., isolated nine natural non-lignin-decomposing fungal strains in crude oil-contaminated soils, including Fusarium, Neurospora, Aspergillus, Scedosporium, Penicillium, Neosartorya and Talaromyces (Reyes-César et al., 2014). Researchers selected Aspergillusterreus, Talaromyces spectabilis, and Fusarium sp. to conduct an experiment on the degradation of naphthalene and pyrene, and the concentration of mixed PAHs was $2,000 \mathrm{mg} / \mathrm{kg}$. After 14 days, about $21 \%$ of the PAH mixture was degraded.

In summary, there are two mechanisms for fungi to impact on the degradation of PAHs, one is the lignin degrading enzyme system, and the other is the single oxygenase degradation system. Lignin degrading enzymes are lignin peroxidase, manganese peroxidase and laccase. These enzymes can convert PAHs into quinone, and subsequently achieve the PAHs degradation with the help of hydrogenation and dehydration (Ryu et al., 2003). As for monooxygenase degradation system, the initial process is adding oxygen to benzene ring to achieve the formation of epoxy compounds based on the catalysis of cytochrome P-450. Then phenol derivatives are generated and combined and rearranged with sulfate, glucose, xylose and glucuronic acid, so as to obtained degradation intermediates with high water solubility and low toxicity (Haritash and Kaushik, 2009; Shoun et al., 1989). No matter which mechanism is used, the 
purpose is to achieve the best results by ensuring the best external conditions to maintain the activity of the enzyme.

In general, biodegradation process is environmentally friendly and is able to remove PAHs completely. More and more scholars are paying attention to it and are working to improve the degradation rate. In addition, the vital role of enzymes can help us better study the biodegradation process of PAHs.

Each method has a significant effect on the degradation of PAHs, but each method has its own characteristics. As shown in Table 1, the advantages and disadvantages of each method are compared, and the average degradation rates that each method can achieve are summarized.

Table 1. The characteristics of different methods

\begin{tabular}{|c|c|c|c|c|}
\hline \multicolumn{2}{|c|}{ Methods } & Advantages & Shortages & $\begin{array}{l}\text { Possible } \\
\text { efficiency }\end{array}$ \\
\hline Physical & $\begin{array}{l}\text { Sorption } \\
\text { Extraction }\end{array}$ & $\begin{array}{l}\text { The material is easy to obtain. } \\
\text { It is cost-effective and } \\
\text { environmental friendly. } \\
\text { The resource can be reused, which } \\
\text { has obvious effects on the } \\
\text { degradation of PAHs. }\end{array}$ & $\begin{array}{l}\text { Although PAHs can be } \\
\text { transferred, they cannot } \\
\text { ber completely } \\
\text { decomposed. } \\
\text { Ther temperature } \\
\text { required to prepare } \\
\text { materials such as } \\
\text { biochar is too high. }\end{array}$ & $60 \%$ \\
\hline Chemical & $\begin{array}{c}\text { Oxidation } \\
\text { Photocatalytic }\end{array}$ & $\begin{array}{l}\text { The degradation rate is extremely } \\
\text { high and the time taken for } \\
\text { degradation is short. }\end{array}$ & \begin{tabular}{|lr} 
The & intermediate \\
produced & by \\
degradation & is likely to \\
cause & secondary \\
pollution. &
\end{tabular} & $85 \%$ \\
\hline Biological & $\begin{array}{l}\text { Plants } \\
\text { Bacteria } \\
\text { Fungi }\end{array}$ & $\begin{array}{l}\text { It is environmentally friendly and it } \\
\text { can degrade PAHs rather than } \\
\text { transfer them. Intermediates do not } \\
\text { cause secondary pollution. }\end{array}$ & $\begin{array}{l}\text { The degradation rate is } \\
\text { lower than the } \\
\text { chemical method and } \\
\text { the cycle is too long. }\end{array}$ & $65 \%$ \\
\hline
\end{tabular}

\section{Conclusion}

Concerning the PAHs pollution, more and more scholars are committed to finding the most effective way to degrade PAHs. Currently, physical, chemical and biological methods have been used to control it. Physical degradation is related to the utilization of activated carbon, bio-carbon, mesoporous silicon and other materials. These materials all feature high specific surface area which is conducive to adsorb polycyclic aromatic hydrocarbon. An appropriate selection of extraction agent is critical to the extraction of PAHs in sludge or water, and external environmental factors such as temperature, $\mathrm{pH}$ value, etc. will influence the extraction efficiency. Compared with physical methods and biodegradation, chemical methods excel in the removal of PAHs. Photocatalysis and oxidation have been proved to facilitate high degradation efficiency. Among the chemical methods, the advanced oxidation technology is the most effective. Its mechanism is about generating lively oxygen which can destroy toxic organic compounds. There is an oxidation reaction between $\bullet \mathrm{OH}$ and $\mathrm{PAHs}$ till carbon dioxide and water are generated. In advanced oxidation, active oxygen production requires external conditions such as ultraviolet light, divalent iron ions, ultrasound, etc. Scientific studies show that the external environment has an obvious influence on the 
oxidation degradation efficiency. For instance, the higher the temperature is, the higher oxidation efficiency will be. Certainly, the combination of photocatalytic and advanced oxidation techniques can also greatly improve the degradation efficiency with the utilization of synergistic effects. The bioremediation efficiency of PAHs depends on the number, type and chemical structure of the microorganisms. The degradation efficiency of various PAHs affected by bacteria or fungi isolated from diverse environments also varies. At present, in PAHs bioremediation, white rot fungi is used the most widely, which can produce a series of enzyme lignin peroxidase, manganese peroxidase and laccase. These enzymes play crucial roles in the PAHs repair and degradation by converting PAHs into simple and less harmful compounds. Mostly, the degradation of PAHs impacted by bacteria and plants is also dependent on their own enzymes.

Physical, chemical and biological methods have their own advantages and disadvantages. The physical method is a good way for PAHs degradation owing to its simplicity, availability and low cost. However, it cannot completely solve the problem by moving PAH pollutants from one place to another. Chemical method can achieve a high degradation rate of PAHs, especially the advanced oxidation technology. But chemical materials may cause secondary pollution to the environment. Biological method is the most environmentally friendly way and it can completely remove PAHs, but it takes at least 15 to 20 days to remove the PAHs. At the same time, the external environment greatly impacts the enzyme activity, and there are many destabilizing factors in the environment.

To sum up, among the three types of methods, the best method is biological method. As for biological methods, the plants, bacteria and fungi are used to produce enzymes to degrade PAHs. Therefore, protecting the activity of enzymes is the key to improve the degradation rate. Storing enzymes in a certain environment can protect their activity and reduce the harm from the outside world. In recent years, metal organic frameworks (MOFs) have been developed rapidly and used in many fields. This kind of material is porous and has large surface area and other characteristics. Therefore, it functions as a kind of adsorption material for the adsorption of polycyclic aromatic hydrocarbon molecules. Combining MOFs and enzyme molecules can fix the enzyme molecule on the material and give full play to its catalysis. The reverse micelle system can provide a suitable place for enzymes, and effectively prevent the destruction of enzymes from external factors. Therefore, it is necessary to explore more effective ways that combine the advantages of physical, chemical and biological methods.

Acknowledgements. The authors acknowledge the financial support from the National Natural Science Foundation of China (51608194), Natural Science Foundation of Hunan (2015JJ3091), and Opening Fund of Key Laboratory of Chemical Biology and Traditional Chinese Medicine Research (Hunan Normal University), Ministry of Education.

\section{REFERENCES}

[1] Alagić, S. Č., Maluckov, B. S., Radojičić, V. B. (2015): How can plants manage polycyclic aromatic hydrocarbons? May these effects represent a useful tool for an effective soil remediation? A Review. - Clean Technologies \& Environmental Policy 17(3): 597-614.

[2] Alagić, S. Č., Jovanović, V. P., Mitić, V. D., Cvetković, J. S., Petrović, G. M., Stojanović, G. S. (2016): Bioaccumulation of HMW PAHs in the roots of wild blackberry 
from the Bor region (Serbia): Phytoremediation and Biomonitoring Aspects. - Science of the Total Environment 562(562): 561-570.

[3] Arun, A., Raja, P. P., Arthi, R., Ananthi, M., Kumar, K. S., Eyini, M. (2008): Polycyclic aromatic hydrocarbons (Pahs) biodegradation by Basidiomycetes fungi, Pseudomonas isolate, and their cocultures: comparative in vivo and in silico approach. - Applied Biochemistry \& Biotechnology 151(2-3): 132-142.

[4] Belo, R. F. C., Figueiredo, J. P., Nunes, C. M., Pissinatti, R., Junqueira, R. G. (2017): Accelerated solvent extraction method for the quantification of polycyclic aromatic hydrocarbons in cocoa beans by gas chromatography-mass spectrometry. - J Chromatogr B Analyt Technol Biomed Life Sci 1053: 87-100.

[5] Beltrán, F. J., Ovejero, G., A., Rivas, J. (1996): Oxidation of polynuclear aromatic hydrocarbons in water. 4. ozone combined with hydrogen peroxide. - Industrial \& Engineering Chemistry Research 35(3): 883-890.

[6] Bernalmartinez, A., Carrère, H., Patureau, D., Delgenès, J. P. (2007): Ozone pretreatment as improver of PAH removal during anaerobic digestion of urban sludge. Chemosphere 68(6): 1013-9.

[7] Bouzid, I., Maire, J., Brunol, E., Caradec, S., Fatin-Rouge, N. (2017): Compatibility of surfactants with activated-persulfate for the selective oxidation of $\mathrm{PAH}$ in groundwater remediation. - Journal of Environmental Chemical Engineering 5(6).

[8] Brown, G. S., Barton, L. L., Thomson, B. M. (2003): Permanganate Oxidation of sorbed polycyclic aromatic hydrocarbons. - Waste Management 23(8): 737-740.

[9] Brown, J. N., Peake, B. M. (2006): Sources of heavy metals and polycyclic aromatic hydrocarbons in urban stormwater runoff. - Science of the Total Environment 359(1): 145-155.

[10] Cerniglia, C. E. (1992): Biodegradation of polycyclic aromatic hydrocarbons. - Current Opinion in Biotechnology 3(2-3): 351-368.

[11] Chen, B., Yuan, M., Hao, L. (2011): Removal of polycyclic aromatic hydrocarbons from aqueous solution using plant residue materials as a biosorbent. - Journal of Hazardous Materials 188(1): 436-442.

[12] Chen, S., Yin, H., Ye, J., Peng, H., Zhang, N., He, B. (2013): Effect of copper (II) on biodegradation of benzo[a]pyrene by Stenotrophomonas maltophilia. - Chemosphere 90(6): 1811-20.

[13] Chulalaksananukul, S., Gadd, G. M., Sangvanich, P., Sihanonth, P., Piapukiew, J., Vangnai, A. S. (2006): Biodegradation of benzo(a)pyrene by a newly isolated fusarium sp. - Fems Microbiology Letters 262(1): 99-106.

[14] Cutright, T. J. (1995): Polycyclic aromatic hydrocarbon biodegradation and kinetics using Cunninghamella echinulata var. Elegans. - International Biodeterioration \& Biodegradation 35(4): 397-408.

[15] Da, S. M., E. Esposito, J. D. Moody, V. P. Canhos \& C. E. Cerniglia (2004) Metabolism of aromatic hydrocarbons by the filamentous fungus Cyclothyrium sp. Chemosphere, 57, 943-952.

[16] Dean-Ross, D., Moody, J., Cerniglia, C. E. (2002): Utilization of mixtures of polycyclic aromatic hydrocarbons by bacteria isolated from contaminated sediment. - Fems Microbiology Ecology 41(1): 1-7.

[17] Debajyoti, G., Shreya, G., Dutta, T. K., Youngho, A. (2016): Current state of knowledge in microbial degradation of polycyclic aromatic hydrocarbons (PAHs): a review. Frontiers in Microbiology 7(386): 1369.

[18] Eberius, M., Berns, A., Schuphan, I. (1997): Ozonation of pyrene and benzo[a]pyrene in silica and soil - 14C-Mass balances and chemical analysis of oxidation products as a first step to ecotoxicological evaluation. - Fresenius Journal of Analytical Chemistry 359(3): 274-279. 
[19] Feng, C., Khulbe, K. C., Matsuura, T., Tabe, S., Ismail, A. F. (2013): Preparation and characterization of electro-spun nanofiber membranes and their possible applications in water treatment. - Separation \& Purification Technology 102(1): 118-135.

[20] Garon, D., Sage, L., Wouessidjewe, D., Seigle-Murandi, F. (2004): Enhanced degradation of fluorene in soil slurry by Absidia cylindrospora and maltosyl-cyclodextrin. Chemosphere 56(2): 159-166.

[21] Gong, Z., Alef, K., Wilke, B. M., Li, P. (2005): Dissolution and removal of PAHs from a contaminated soil using sunflower oil. - Chemosphere 58(3): 291.

[22] Hadibarata, T., Kristanti, R. A. (2014): Fluorene biodegradation and identification of transformation products by white-rot fungus Armillaria sp. F022. - Biodegradation 25(3): 373-382.

[23] Hadibarata, T., Teh, Z. C., Rubiyatno, Zubir, M. M., Khudhair, A. B., Yusoff, A. R., Salim, M. R., Hidayat, T. (2013): Identification of naphthalene metabolism by white rot fungus Pleurotus eryngii. - Bioprocess \& Biosystems Engineering 36(10): 1455-1461.

[24] Haritash, A. K., Kaushik, C. P. (2009): Biodegradation aspects of polycyclic aromatic hydrocarbons (PAHs): a review. - Journal of Hazardous Materials 169(1-3): 1.

[25] Hiller, E., Jurkovič, L., Bartal, M. (2008): Effect of temperature on the distribution of polycyclic aromatic hydrocarbons in soil and sediment. - Soil \& Water Research 3(4): 231-240.

[26] Homem, V., Dias, Z., Santos, L., Alves, A. (2014): Preliminary feasibility study of benzo(a)pyrene oxidative degradation by fenton treatment. - Journal of Environmental \& Public Health 2009(2009):: 149034.

[27] Huang, Y., Fulton, A. N., Keller, A. A. (2016): Simultaneous removal of PAHs and metal contaminants from water using magnetic nanoparticle adsorbents. - Science of the Total Environment 571: 1029-1036.

[28] Ji, H., Gong, Y., Duan, J., Zhao, D., Liu, W. (2018): Degradation of petroleum hydrocarbons in seawater by simulated surface-level atmospheric ozone: reaction kinetics and effect of oil dispersant. - Marine Pollution Bulletin 135: 427-440.

[29] Jiang, L., Yuan, X., Zeng, G., Wu, Z., Liang, J., Chen, X., Leng, L., Wang, H., Wang, H. (2017): Metal-free efficient photocatalyst for stable visible-light photocatalytic degradation of refractory pollutant. - Applied Catalysis B Environmental 221.

[30] Jiang, L., Yuan, X., Zeng, G., Liang, J., Chen, X., Yu, H., Wang, H., Wu, Z., Zhang, J., Xiong, T. (2018): In-situ synthesis of direct solid-state dual Z-scheme $\mathrm{WO}_{3} / \mathrm{g}-\mathrm{C}_{3} \mathrm{~N}_{4} / \mathrm{Bi}_{2}$ $\mathrm{O}_{3}$ photocatalyst for the degradation of refractory pollutant. - Applied Catalysis B Environmental 227.

[31] Jin, X., Tian, W., Liu, Q., Qiao, K., Zhao, J., Gong, X. (2017): Biodegradation of the benzo[A]pyrene-contaminated sediment of the Jiaozhou bay wetland using Pseudomonas sp. immobilization. - Marine Pollution Bulletin 117(1-2): 283.

[32] Kalmykova, Y., Moona, N. (2014): Sorption and degradation of petroleum hydrocarbons, polycyclic aromatic hydrocarbons, alkylphenols, bisphenol A and phthalates in landfill leachate using sand, activated carbon and peat filters. - Water Research 56(3): 246-257.

[33] Khattri, S. D., Singh, M. K. (2009): Removal of malachite green from dye wastewater using neem sawdust by adsorption. - Journal of Hazardous Materials 167(1-3): 10891094.

[34] Kristanti, R. A., Hadibarata, T. (2015): Biodegradation and identification of transformation products of fluorene by Ascomycete fungi. - Water Air \& Soil Pollution 226(12): 1-6.

[35] Kronenberg, M., Trably, E., Bernet, N., Patureau, D. (2017): Biodegradation of polycyclic aromatic hydrocarbons: using microbial bioelectrochemical systems to overcome an impasse. - Environmental Pollution 231(Pt 1): 509.

[36] Kuppusamy, S., Thavamani, P., Megharaj, M., Naidu, R. (2016): Biodegradation of polycyclic aromatic hydrocarbons (PAHs) by novel bacterial consortia tolerant to diverse 
physical settings - assessments in liquid-and slurry-phase systems. - International Biodeterioration \& Biodegradation 108: 149-157.

[37] Lair, A., Ferronato, C., Chovelon, J. M., Herrmann, J. M. (2008): Naphthalene degradation in water by heterogeneous photocatalysis: An investigation of the influence of inorganic anions. - Journal of Photochemistry \& Photobiology A Chemistry 193(2-3): 193-203.

[38] Lambropoulou, D. A. (2010): An overview of modern extraction techniques for the determination of organic pollutants in environmental matrices: a review. - Current Organic Chemistry 14(19): -.

[39] Lamichhane, S., Krishna, K. C. B., Sarukkalige, R. (2016): Polycyclic aromatic hydrocarbons (PAHs) removal by sorption: a review. - Chemosphere 148: 336-353.

[40] Lau, E. V., Gan, S., Ng, H. K., Poh, P. E. (2014): Extraction agents for the removal of polycyclic aromatic hydrocarbons (PAHs) from soil in soil washing technologies. Environmental Pollution 184(1): 640.

[41] Ledakowicz, S. A., Miller, J. S., Olejnik, D. (2014): Oxidation of PAHs in water solution by ozone combined with ultraviolet radiation. - International Journal of Photoenergy 3(1): 95-101.

[42] Lei, A. P., Hu, Z. L., Wong, Y. S., Tam, N. F. (2007): Removal of fluoranthene and pyrene by different microalgal species. - Bioresource Technology 98(2): 273-80.

[43] Li, Z., Liu, Y., Yang, X., Xing, Y., Yang, Q., Yang, R. T. (2017): Adsorption thermodynamics and desorption properties of gaseous polycyclic aromatic hydrocarbons on mesoporous adsorbents. - Adsorption-journal of the International Adsorption Society 23(2-3): 361-371.

[44] Liu, G., Niu, Z., Niekerk, D. V., Xue, J., Zheng, L. (2008): Polycyclic aromatic hydrocarbons (PAHs) from coal combustion: emissions, analysis, and toxicology. Reviews of Environmental Contamination \& Toxicology 192: 1.

[45] Llobet, J. M., Falcó, G., Bocio, A., Domingo, J. L. (2006): Exposure to polycyclic aromatic hydrocarbons through consumption of edible marine species in Catalonia, Spain. - J Food Prot 69(10): 2493-2499.

[46] Lu, J., Guo, C., Zhang, M., Lu, G., Dang, Z. (2014): Biodegradation of single pyrene and mixtures of pyrene by a fusant bacterial strain F14. - International Biodeterioration \& Biodegradation 87: 75-80.

[47] Luna, F. M. T., Filho, A. N. O., Araújo, C. C. B., Azevedo, D. C. S., Jr, C. L. C. (2016): Adsorption of polycyclic aromatic hydrocarbons from heavy naphthenic oil using commercial activated carbons. 2. column adsorption studies. - Industrial \& Engineering Chemistry Research 55(29).

[48] Mahler, B. J., Metre, P. C. V., Crane, J. L., Watts, A., Scoggins, M., Williams, E. S. (2012): Coal-tar-based pavement seal coat and PAHs: Implications for the environment, human health, and stormwater management. - Environmental Science \& Technology 46(6): 3039-45.

[49] Marcourrea, E., Aranda, E. (2015): Potential of non-ligninolytic fungi in bioremediation of chlorinated and polycyclic aromatic hydrocarbons. - New Biotechnology 32(6): 620628.

[50] Mohanrasu, K., Premnath, N., Siva Prakash, G., Sudhakar, M., Boobalan, T., Arun, A. (2018): Exploring multi potential uses of marine bacteria; an integrated approach for PHB production, PAHs and polyethylene biodegradation. - Journal of Photochemistry and Photobiology B: Biology 185: 55-65.

[51] Muangchinda, C., Yamazoe, A., Polrit, D., Thoetkiattikul, H., Mhuantong, W., Champreda, V., Pinyakong, O. (2016): Biodegradation of high concentrations of mixed polycyclic aromatic hydrocarbons by indigenous bacteria from a river sediment: a microcosm study and bacterial community analysis. - Environmental Science and Pollution Research 24(5): 4591-4602. 
[52] Niu, J., Dai, Y., Guo, H., Xu, J., Shen, Z. (2013): Adsorption and transformation of PAHs from water by a laccase-loading spider-type reactor. - Journal of Hazardous Materials 248-249C(6): 254.

[53] Noordkamp, E. R., Grotenhuis, J. T. C., Rulkens, W. H. (1997): Selection of an efficient extraction method for the determination of polycyclic aromatic hydrocarbons in contaminated soil and sediment. - Chemosphere 35(9): 1907-1917.

[54] Nzila, A. (2018): Biodegradation of high-molecular-weight polycyclic aromatic hydrocarbons under anaerobic conditions: overview of studies, proposed pathways and future perspectives. - Environ Pollut 239: 788-802.

[55] Oleszczuk, P., Hale, S. E., Lehmann, J., Cornelissen, G. (2012): Activated carbon and biochar amendments decrease pore-water concentrations of polycyclic aromatic hydrocarbons (PAHs) in sewage sludge. - Bioresource Technology 111(111): 84-91.

[56] Pérez, M., Torrades, F., Domènech, X., Peral, J. (2002): Fenton and photo-fenton oxidation of textile effluents. - Water Research 36(11): 2703.

[57] Passarini, M. R., Rodrigues, M. V., da Silva, M., Sette, L. D. (2011): Marine-derived filamentous fungi and their Potential application for polycyclic aromatic hydrocarbon bioremediation. - Mar Pollut Bull 62(2): 364-70.

[58] Ríos, Á., Zougagh, M. (2016): Recent advances in magnetic nanomaterials for improving analytical processes. - Trac Trends in Analytical Chemistry 84: 72-83.

[59] Rahman, R. N., Ghaza, F. M., Salleh, A. B., Basri, M. (2006): Biodegradation of hydrocarbon contamination by immobilized bacterial cells. - Journal of Microbiology 44(3): 354-359.

[60] Ramasamy, V., Anandan, C., Murugadoss, G. (2013): Structural, morphological and photoluminescence studies of multi shells coated $\mathrm{ZnO}$ nanocomposites. - Superlattices \& Microstructures 61(9): 106-114.

[61] Ravindra, K., Grieken, S. R. V. (2008): Atmospheric polycyclic aromatic hydrocarbons: source attribution, emission factors and regulation. - Atmospheric Environment 42(13): 2895-2921.

[62] Rehmann, K., Noll, H. P., Steinberg, C. E., Kettrup, A. A. (1998): Pyrene degradation by Mycobacterium sp. Strain KR2. - Chemosphere 36(14): 2977-2992.

[63] Reyes-César, A., Absalón, Á. E., Fernández, F. J., González, J. M., Cortés-Espinosa, D. V. (2013): Biodegradation of a mixture of PAHs by non-ligninolytic fungal strains isolated from crude oil-contaminated soil. - World Journal of Microbiology and Biotechnology 30(3): 999-1009.

[64] Rhodes, A. H., Carlin, A., Semple, K. T. (2008): Impact of black carbon in the extraction and mineralization of phenanthrene in soil. - Environmental Science \& Technology 42(3): 740.

[65] Romero, M. C., Cazau, M. C., Giorgieri, S., Arambarri, A. M. (1998): Phenanthrene degradation by microorganisms isolated from a contaminated stream. - Environmental Pollution 101(3): 355-359.

[66] Rubio-Clemente, A., Torres-Palma, R. A., Peñuela, G. A. (2014): Removal of polycyclic aromatic hydrocarbons in aqueous environment by chemical treatments: a review. Science of the Total Environment 478(8): 201-225.

[67] Ruge, Z., Muir, D., Helm, P., Lohmann, R. (2015): Concentrations, trends, and air-water exchange of PAHs and PBDEs derived from passive samplers in lake superior in 2011. Environmental Science \& Technology 49(23): 13777-13786.

[68] Ryu, W. Y., Jang, M. Y., Cho, M. H. (2003): The selective visualization of lignin peroxidase, manganese peroxidase and laccase, produced by white rot fungi on solid media. - Biotechnology \& Bioprocess Engineering 8(2): 130-134.

[69] Sáncheztrujillo, M. A., Morillo, E., Villaverde, J., Lacorte, S. (2013): Comparative effects of several cyclodextrins on the extraction of PAHs from an aged contaminated soil. - Environmental Pollution 178: 52-58. 
[70] Sarma, P. M., Duraja, P., Deshpande, S., Lal, B. (2010): Degradation of pyrene by an enteric bacterium, Leclercia adecarboxylata PS4040. - Biodegradation 21(1): 59.

[71] Shi, W., Guo, Y., Ning, G., Li, C., Li, Y., Ren, Y., Zhao, O., Yang, Z. (2018): Remediation of soil polluted with HMW-PAHs by alfalfa or brome in combination with fungi and starch. - Journal of Hazardous Materials 360: 115-121.

[72] Shoun, H., Sudo, Y., Sato, K. I., Beppu, T. (1989): Components of the cytochrome P-450 monooxygenase system of the fungus, Fusarium oxysporum: conditions for induction and isolation of cytochrome b5. - Journal of the Agricultural Chemical Society of Japan 53(8): 2153-2161.

[73] Silva, A., Delerue-Matos, C., Fiúza, A. (2005): Use of solvent extraction to remediate soils contaminated with hydrocarbons. - Journal of Hazardous Materials 124(1-3): 224229.

[74] Silva, I. S., Grossman, M., Durrant, L. R. (2009): Degradation of polycyclic aromatic hydrocarbons (2-7 rings) under microaerobic and very-low-oxygen conditions by soil fungi. - International Biodeterioration \& Biodegradation 63(2): 224-229.

[75] Silva, M. D. (2002): Fungos filamentosos isolados de sedimentos estuarinos que metabolizam hidrocarbonetos aromaticos policiclicos. - Tese (doutorado), Universidade Estadual de Campinas, Faculdade de Engenharia de Alimentos, Campinas, SP.

[76] Somtrakoon, K., Chouychai, W., Lee, H. (2014): Comparing anthracene and fluorene degradation in anthracene and fluorene-contaminated soil by single and mixed plant cultivation. - Int J Phytoremediation 16(4): 415-428.

[77] Song, W., Li, J., Zhang, W., Hu, X., Wang, L. (2012): An experimental study on the remediation of phenanthrene in soil using ultrasound and soil washing. - Environmental Earth Sciences 66(5): 1487-1496.

[78] Souza, H. M. D. L., Sette, L. D., Mota, A. J. D., Rodrigues, A., Oliveira, T. B. D., Oliveira, F. M. D., Oliveira, L. A. D., Barroso, H. D. S., Zanotto, S. P. (2016): Filamentous fungi isolates of contaminated sediment in the Amazon region with the potential for benzo(a)pyrene degradation. - Water Air \& Soil Pollution 227(12): 431.

[79] Sprovieri, M., Feo, M. L., Prevedello, L., Manta, D. S., Sammartino, S., Tamburrino, S., Marsella, E. (2007): Heavy metals, polycyclic aromatic hydrocarbons and polychlorinated biphenyls in surface sediments of the Naples harbour (southern Italy). Chemosphere 67(5): 998-1009.

[80] Sun, K., Liu, J., Jin, L., Gao, Y. (2014): Utilizing pyrene-degrading endophytic bacteria to reduce the risk of plant pyrene contamination. - Plant \& Soil 374(1-2): 251-262.

[81] Szczepaniak, Z., Cyplik, P., Juzwa, W., Czarny, J., Staninska, J., Piotrowska-Cyplik, A. (2015): Antibacterial effect of the Trichoderma viride Fungi on soil microbiome during PAH's biodegradation. - International Biodeterioration \& Biodegradation 104: 170-177.

[82] Szulejko, J. E., Kim, K. H., Brown, R. J. C., Bae, M. S. (2014): Review of progress in solvent-extraction techniques for the determination of polyaromatic hydrocarbons as airborne pollutants. - Trends in Analytical Chemistry 61(5): 40-48.

[83] Tiwari, M., Sahu, S. K., Bhangare, R. C., Ajmal, P. Y., Pandit, G. G. (2013): Estimation of polycyclic aromatic hydrocarbons associated with size segregated combustion aerosols generated from household fuels. - Microchemical Journal 106(1): 79-86.

[84] Veignie, E., Rafin, C., Woisel, P., Cazier, F. (2004): Preliminary evidence of the role of hydrogen peroxide in the degradation of benzo[a]pyrene by a non-white rot fungus Fusarium solani. - Environmental Pollution 129(1): 1-4.

[85] Vela, N., Martínez-Menchón, M., Navarro, G., Pérez-Lucas, G., Navarro, S. (2012): Removal of polycyclic aromatic hydrocarbons (PAHs) from groundwater by heterogeneous photocatalysis under natural sunlight. - Journal of Photochemistry \& Photobiology A Chemistry 232(5): 32-40.

[86] Veréb, G., Ambrus, Z., Pap, Z., Kmetykó, Á., Dombi, A., Danciu, V., Cheesman, A., Mogyorósi, K. (2012): Comparative study on UV and visible light sensitive bare and 
doped titanium dioxide photocatalysts for the decomposition of environmental pollutants in water. - Applied Catalysis A General 417-418(1): 26-36.

[87] Von, L. E., Gan, S., Ng, H. K. (2012): Extraction of phenanthrene and fluoranthene from contaminated sand using palm kernel and soybean oils. - Journal of Environmental Management 107(107): 124-130.

[88] Waszak, D. Q., Cunha, A. C. B. D., Agarrallua, M. R. A., Goebel, C. S., Sampaio, C. H. (2015): Bioremediation of a benzo[a]pyrene-contaminated soil using a microbial consortium with Pseudomonas aeruginosa, Candida albicans, Aspergillus flavus, and Fusarium sp. - Water Air \& Soil Pollution 226(9): 1-11.

[89] Wen, S., Zhao, J., Sheng, G., Fu, J., Peng, P. (2002): Photocatalytic reactions of pyrene at $\mathrm{TiO}_{2} /$ water interfaces. - Chemosphere 46(6): 871-7.

[90] Woo, O. T., Chung, W. K., Wong, K. H., Chow, A. T., Wong, P. K. (2009): Photocatalytic oxidation of polycyclic aromatic hydrocarbons: intermediates identification and toxicity testing. - Journal of Hazardous Materials 168(2): 1192-1199.

[91] Wu, Y.-R., He, T.-T., Lun, J.-S., Maskaoui, K., Huang, T.-W., Hu, Z. (2009): Removal of benzo[a]pyrene by a fungus Aspergillus sp. BAP14. - World Journal of Microbiology and Biotechnology 25(8): 1395-1401.

[92] Xia, W., Du, Z., Cui, Q., Dong, H., Wang, F., He, P., Tang, Y. (2014): Biosurfactant produced by novel pseudomonas sp. WJ6 with biodegradation of $\mathrm{N}$-alkanes and polycyclic aromatic hydrocarbons. - Journal of Hazardous Materials 276(5): 489-498.

[93] Yenchih Chen, And, M. K. B., Schwab, A. P. (2003): Pyrene degradation in the rhizosphere of tall fescue (Festuca arundinacea) and switchgrass (Panicum virgatum L.). - Environmental Science \& Technology 37(24): 5778-82.

[94] Yongwoon, L., Jinje, P., Gang, K. S., Changkook, R., Yang, W., Jinho, J., Seunghun, H. (2013): Production and characterization of biochar from various biomass materials by slow pyrolysis. - Technical Bulletin (Asian and Pacific Council, Food \& Fertilizer Technology Center) no. 197.

[95] Yuan, M., Tong, S., Zhao, S., Jia, C. Q. (2010): Adsorption of polycyclic aromatic hydrocarbons from water using petroleum coke-derived porous carbon. - Journal of Hazardous Materials 181(1-3): 1115.

[96] Yuan, Q., Posch, T., Schmidt, T. C. (2011): Sorption of polycyclic aromatic hydrocarbons (PAHs) on glass surfaces. - Chemosphere 82(6): 859-865.

[97] Zeledón-Toruño, Z. C., Lao-Luque, C., Heras, F. X. C. D. L., Sole-Sardans, M. (2007): Removal of PAHs from water using an immature coal (leonardite). - Chemosphere 67(3): 505-512.

[98] Zhang, S., Ning, Y., Zhang, X., Zhao, Y., Yang, X., Wu, K., Yang, S., La, G., Sun, X., $\mathrm{Li}, \mathrm{X}$. (2015): Contrasting characteristics of anthracene and pyrene degradation by wood rot fungus Pycnoporus sanguineus H1. - International Biodeterioration \& Biodegradation 105: 228-232.

[99] Zhang, W., Sun, H., Wang, L. (2013): Influence of the interactions between black carbon and soil constituents on the sorption of pyrene. - Journal of Soil Contamination 22(4): 469-482. 